\title{
Evaluation of Interpretation and Implementation of the Newly Revised School Curriculum in Zambia: A Case of Schools in Chongwe District of Lusaka Province
}

\author{
Article by Sikalumbi Arona Dewin \\ Chalimbana University, P/Bag E1, Lusaka, Zambia \\ E-mail:adsikalumbi@gmail.com,dewinarona@gmail.com
}

\begin{abstract}
The study evaluated the interpretation and implementation of the newly revised curriculum in primary and secondary schools in Chongwe district of Lusaka province in Zambia. The ascertaining of the effectiveness of the newly revised school curriculum calls for establishing the purpose of learning in Zambian schools today. The study employed a descriptive survey design. The target population comprised of the public and private school Head teachers, teachers, pupils, and district education officers who are mandated to set standards in Zambian schools and ensure that every school meets the minimum standard. The study used purposeful and randomly sampling techniques. Questionnaires, interview guide and observation were used as research instruments to collect data. The study reveals that $31 \%$ of the schools have just implemented the academic career pathway only which is a blue print of the old curriculum and $30 \%$ of the head teachers still prefer the old curriculum to the new one. It has also been observed that the implementation of the new school curriculum was launched before the schools were made ready. Therefore, the old strategies, school routines and resources for the old curriculum are being used to force the implementation of the newly revised curriculum. The study thus recommends more investment in the Ministry of General Education for more school orientations and close monitoring of the interpretation and implementation of the school curriculum.
\end{abstract}

Keywords: Curriculum, career pathways, academic pathway, vocational pathway, implementation.

\section{Background}

Just like other countries, Zambia is undergoing rapid socio-economic development and the education sector is no exception. Education is an agent of change. While education has always been perceived as a social sector, it is also an economic tool for development.

Education plays the wider role in economic development of societies. This implies that for individuals to fully function in a particular society, they need to have knowledge, skills and positive attitudes which can enable them to function effectively in it. Taneja V. R (2013, p.g 17) observes, "Education must fit the pupil to environment so that he (she) may survive while enjoying the pleasure of satisfying his instincts." Taneja V. R. (2012) also observed that education is a conscious purpose to train the children for fulfilling the responsibility of adult life. This calls for quality education. Without it school leavers experience poverty and unemployment and some get involved into criminal activities.

In every sense, education is one of the fundamental factors of development (Cowes Alain O., 2011). No country can achieve sustainable economic development without substantial investment in human capital (Ouimet, J.A. and Smallwood, R.A., 2005; Christensen \& Allison, 2017). It improves the quality of life and leads to broad social and economic benefits to individuals and society. Education advances people's productivity, inventiveness and promotes entrepreneurship and technological advances. Furthermore, it plays a very critical role in securing economic and social progress and improving income distribution. Not only should a person learn to fit in the environment but should also learn how to modify it to make his life convenient and enjoyable (Kasanda, 2009; Paul Eggen and Don Kauchak, 2010; David Stocks and Nick Wilson, 2017). However, this all centres on the type of curriculum offered in schools and how it is offered to the learners. It is therefore, through a good curriculum that learners should acquire these needed knowledge, skills and positive attitudes if they are to be instrumental in economic development of any given society. 
In 2011, Zambia realised the gap that existed between the school leavers/graduates and the expectation of society and embarked on education transformation. The target was the school curriculum. It was observed that the old curriculum was not addressing the needs of society adequately hence the need to come up with the new curriculum. The newly revised school curriculum was formulated in 2012, launched in January, 2013 and implemented in January, 2014. Dr. John Phiri, by then the Minister of General Education, stressed out that the new curriculum was the only tool for the Ministry of Education to be producing school leavers who are entrepreneurial and instrumental to the economic transformation of the nation. Chongwe district of Lusaka province joined the rest of the districts in Zambia in implementing the revised curriculum.

Chongwe is a peri-urban district located $45 \mathrm{~km}$ East of Lusaka town, the capital city of Zambia. Because of its location it has been used by the government and NGOs for conducting studies as well as for pilot projects before they are implemented in the rest of the districts in Zambia.

The challenges that rural districts may face in curriculum implementation may not be the same as those in urban districts. Therefore, Chongwe district being a peri-urban district was chosen in this study so as to come up with a more balanced report.

\section{Problem statement}

As the needs and aspirations of society change, so should the school curriculum. To address the needs of the Zambian society, the government of the republic of Zambia launched the new school curriculum in 2013 and it was implemented in schools in 2014. The curriculum aimed at equipping the learners with skills so as to transform societies towards social and economic development. Developing a good school curriculum is one thing, interpreting and implementing it successfully is another. In as much as there has been more documentation regarding the learner academic performance among others in Chongwe district for the past five years, less has been documented regarding the effectiveness in the interpretation and implementation of the revised school curriculum after three and half years since it was launched. This rose the need to fill this gap by establishing the effectiveness in the interpretation and implementation of the revised curriculum in schools. Hence the study.

\section{Research objectives}

The research objectives of the study were to;

- To investigate the interpretation of the new curriculum in schools in Chongwe district.

- Assess the implementation of the career pathways in schools in Chongwe district.

- Suggest measures to enhance the implementation of the new curriculum in schools.

\section{Research questions}

- How has the new curriculum interpreted in schools in Chongwe district?

- To what extent have the career pathways implementation in schools in Chongwe district?

- What measures should be put in place to enhance the implementation of the new curriculum in schools?

\section{Methodology}

The study employed a descriptive survey design. The target population comprised of the public and private school Head teachers, teachers, pupils, and district education officers in Chongwe who are mandated to set standards in Zambian schools. Chongwe district by the time of the study had 7 secondary schools and 35 primary schools, making a total of 42 schools with 1200 teachers and 9 principal officers at the district education office. The sample size was $24 \%$ of the total schools, $5 \%$ of the total number of teachers and 33\% of the district education principal officers in Chongwe. The study used purposive sampling technique when choosing the head teachers and District Education Officers and randomly sampling technique when choosing schools, teachers, and pupils. Questionnaires, interview guide and observation were used as research instruments to collect data. After gathering data, it was analysed using the Statistical Packages for Social Sciences (SPSS) so as to draw conclusions. 


\section{The national curriculum for schools}

The term curriculum refers to "All that is taught in school including the timetabled subjects and all those aspects of its life that exercise an influence in the life of the children," Farrant J. S (1980, p.g 24). However, Taneja V. R (2013, p.g 292) defines curriculum as "the instructional and the educative programme by following which the pupils achieve their goals, ideals and aspirations of life." Depending on how broadly educators define or employ the term, curriculum typically refers to the knowledge, skills, attitudes and values which students are expected to acquire; which includes the learning specifications and standards or learning aims, goals and objectives they are expected to meet; the units, content and lessons that teachers teach; the assignments and projects given to students; the books, materials, videos, presentations, field trips and readings used in a course; and the tests, assessments, and other methods used to evaluate student learning.

In 1996, the Ministry of Education developed the National Policy on Education, 'Educating Our Future', in order to respond to the developmental needs of the nation as well as those of the individual learners (MOE, 1996). This policy has since become the basis of all the educational strategies that ensure the provision of quality education through suitable teaching and learning at all levels of education in Zambia. It is against this background that the Zambia Education Curriculum Framework (ZECF) was developed in 2013 as the national curriculum to provide further guidance on the preferred type of education for the nation. This ZECF, therefore, provides the curriculum guidelines as well as the structure at all the levels, from Early Childhood Education (ECE) to Tertiary Education and Adult Literacy (MOE, 2013). This national curriculum was implemented in all the Zambian schools in 2014.

MOE (2012) observes on the new curriculum, "Since curriculum is one of the foundational elements of effective schooling and teaching, it is often the object of reforms, most of which are broadly intended to either mandate or encourage greater curricular standardization and consistency across states, schools, grade levels, subject areas, and courses."

The Zambia Education Curriculum Framework (2013) indicates that the philosophical rationale for educational provision is to nurture the holistic development of all individuals and to promote the social and economic welfare of society. To pursue this rationale, the ministry developed two career pathways for secondary schools.

\section{The career pathways and the two-tier system}

Career Pathways have been created in the curriculum to meet the needs and ambitions of different learners. "To carter for diverse interests, differentiated curriculum is essential," (Ewell, P.T., 2010; Taneja V. R., 2013). Hence the ministry of General education has developed two career pathways namely; academic, and vocational and technical career pathways (Education Curriculum Framework, 2012). The vocational and technical career pathway promotes practical skill acquisition and knowledge while the academic career pathway is for learners who wish to study only academic subjects (Teachers' curriculum Implementation Guide, 2013).

In the new curriculum, some subjects have been phased out, others combined like Civics, Geography and History to make Social Studies; Office Practice and Book Keeping to make Business Studies at Junior Secondary level. Furthermore, Computer Studies has been introduced from Grade $1-12$ to address the needs of the Zambian society and world over. Some subjects have been made more practical like Integrated Science; and new important concepts have been introduced to make the subjects more meaningful. However, the interpretation and implementation of this newly revised school curriculum deserves much attention more especially in Chongwe district and this could only be reviewed by visiting schools where this new curriculum was being implemented.

\section{Findings}

To establish the extent to which the newly revised school curriculum has been interpreted and implemented in schools, 10 Head teachers and 40 teachers were interviewed making a sample of $24 \%$ and 5\% of the total schools and teachers respectively in Chongwe district. All the respondents confirmed that they had implemented the new curriculum in schools. However, they rated average the following; their interpretation and implementation of the new curriculum, Career Guidance and Counselling services offered, and Teachers' interpretation and implementation of the new syllabi. These three are 
cardinal in the implementation of the new curriculum but none is rated above average. Why did they rate them average? The following findings justify their rating. On curriculum orientation, $30 \%$ of the sampled teachers confirmed that they had never attended any curriculum orientation seminar or workshop since its implementation in 2014 and $70 \%$ of those who attended rated the orientation exercise fairly and never oriented their colleagues upon arrival. This shows that $30 \%$ of the teachers who never had curriculum orientation have no proper direction on what to implement, how to implement it and for what purpose. Hence the Head teachers were very right when they rated teachers' interpretation and implementation of the new syllabi as average. The study indicates that this was due to inadequate orientation and supervision by both internal and external monitors who are mandated to set standards.

\section{Monitoring}

The research findings indicate that $33 \%$ of the sampled schools had never been monitored by both the Senior Education Standard Officers (SESOs) and the District Education Standard Officers (DESOs) on new curriculum interpretation and implementation since its inception in 2014. There has been no confirmation or correction to $33 \%$ of the schools regarding curriculum interpretation and implementation by external monitors. This means that for three and half years, these schools have continued moving in whatever direction they have taken and there is no one to praise them or correct them where they have gone wrong.

\section{Career pathways}

The study reveals that only $60 \%$ of the sampled schools have implemented both the academic and vocational career pathways as stated in ZECF (2014) while $40 \%$ have just opted for the academic career pathway which is in line with the old curriculum. The $60 \%$ of the schools who said they had both career pathways implemented were heavily hit by lack of text books for new syllabi, lack of computers for I.C.T, lack of science kits and equipment for practical subjects and ill qualified teachers especially in Business Studies, practical subjects, I.C.T and Sciences. Some of the primary school trained teachers who were teaching the junior secondary classes revealed to the researcher that they were teaching those classes just because there was no one in school to handle such subjects. The ultimate result has been poor academic performance in those subjects and non-acquisition of the needed knowledge, skills and values that are needed to steer the social and economic development.

The $40 \%$ of the schools that indicated that they just have the academic career pathway implies that they have no vocational and technical skills to offer to pupils in schools. In some schools, it was due to ignorance while others it was due to lack of teaching and learning materials, non-qualified staff in certain specialised subjects, and inadequate funding. However, the study reveals that $90 \%$ of the respondents indicated that there was inadequate teaching and learning materials for the new curriculum syllabi. This implies that the schools were not adequately prepared for the implementation of the new school curriculum.

\section{Conclusion}

The study reveals that schools were not prepared for the new curriculum implementation, some teachers have not been oriented; $40 \%$ of the schools do not have the vocational pathway, the Career Guidance and Counselling services are inadequate, the teaching and learning materials available are not supporting the new curriculum, and the Education Standards Officers are not adequately monitoring schools to set the standards by giving a close supervision to all schools. If there will be no quick interventions, it will be the old curriculum running in the name of the new curriculum.

The curriculum has not been implemented successfully as most schools have opted for the academic pathway only which was the basis of the old curriculum despite the vocational pathway being compulsory. This is as a result of lack of knowledge by many teachers and Head teachers, having a negative attitude towards the new curriculum, politicising the new curriculum, lack of qualified teachers, and lack of teaching and learning resources for vocational subjects. Schools were not adequately prepared for the implementation of the new school curriculum.

Based on the findings of this research, the following are the recommendations: 
i. The Ministry of General Education should consider investing more in education in line with the human capital theory especially at primary level. This will help to support efforts aimed at implementing the new school curriculum successfully. The ministry should invest more in curriculum implementation by purchasing all the needed teaching and learning resources more especially in practical/vocational subjects and conduct intensive in-service training on the new curriculum implementation. As the colleges and universities are restructuring their curricular to address the demands of the new national curriculum for the trainee teachers, the Ministry of General Education should conduct workshops for in-service teachers about curriculum and syllabi interpretation and implementation.

ii. There is need to consider the speed up of the decentralisation process in decision making in education provision. This will not only help to stop delays associated with disbursing of funds but it will also enhance effectiveness in curriculum development, interpretation and implementation as schools will be engaged at every stage of curriculum development and implementation.

\section{Reference}

[1]. Carmody B. (2004) The Evolution of Education in Zambia, Lusaka: Book World Publishers. Chistensen \& Allison (2017) Research with children; Perspectives and practices, $3^{\text {rd }}$ Ed. Routledge.

[2]. David Stocks and Nick Wilson (2017) Small Business management and entrepreneurship, $7^{\text {th }}$ Ed. Cengage learning EMEA, UK.

[3]. Ewell, P.T. (2010), The US national survey of student engagement (NSSE), in Dill, D.D. and Beerkens, M. (Eds), Public Policy for Academic Quality, Vol. 30, Springer Science+Business Media, Neth, pp. 83-97.

[4]. Ministry of Education (1977) Educational Reforms: Proposals and Recommendations, Lusaka: MOE.

[5]. Ministry of Education (1996) Educating our Future, Lusaka: MOE.

[6]. Mwanakatwe J (1968) The Growth of Education in Zambia since independence, Lusaka: Oxford Press.

[7]. Ouimet, J.A. and Smallwood, R.A. (2005), "CLASSE - the class-level survey of student engagement", Assessment Update, Vol. 17 No. 6, pp. 13-5.

[8]. Pittaway, L., Hannon, P., Gibb, A.A. and Thompson, J. (2009), "Assessment practice in enterprise education", International Journal of Entrepreneurial Behaviour \& Research, Vol. 15 No. 1, pp. 71-93.

[9]. Sherman, P.S., Sebora, T. and Digman, L.A. (2008), "Experiential entrepreneurship in the classroom: effects of teaching methods on entrepreneurial career choice intentions", Journal of Entrepreneurship Education, Vol. 11, pp. 29-42.

[10]. Tajena V. R (2012) Education thought and practice, Sterling publishers private limited, New Delhi, India.

[11]. UNESCO (2007) Experts' Consultation on the Operational Definition of Basic Education.

[12]. Uwakwe C B, Falaye A O, Adelore O (2008) Impact of Decentralization and Privatization on the Quality of Education in Sub-Saharan Africa: The Nigerian Experience, European Journal of Social Sciences - Volume 7, Number.

[13]. Vaughan, N.D. (2010), "Blended community of inquiry approach: linking student engagement and course redesign", Internet and Higher Education, Vol. 13 Nos 1-2, pp. 60-5. 